\title{
Sexual Dimorphism in Foot Print Ratio
}

\author{
M. A. Rahman ${ }^{1}$, A. A. Mahajan ${ }^{2}$, A. G. Shroff ${ }^{3}$ \\ ${ }^{1}$ (Department of Anatomy, SRTR Government Medical College Ambajogai, Maharashtra University of Health \\ Sciences Nashik, India) \\ ${ }^{2}$ (Department of Anatomy, Jalgaon Medical College, Maharashtra University of Health Sciences Nashik, India) \\ ${ }^{3}$ (Dean, Mahatma Gandhi Medical College, Mahatma Gandhi University of Health Sciences, Aurangabad, \\ India)
}

\begin{abstract}
Establishing sex by the foot print study is rather a new approach in the ever expanding research subject of human identity. The Foot Print Ratio (FPR) is derived as a ratio between the two parameters of the foot prints i.e. the maximum width and maximum length, measured in millimeters. Four hundred dermatoglyphic foot prints of 100 males \&100 females were obtained from the staff and undergraduate students of Government Medical College Aurangabad. Maximum Length and Maximum Breadth were calculated. The Footprints Ratio (FPR) for both left and right foot prints of each individual in the study group was calculated separately and values obtained were analyzed statistically. Statistical analysis showed that Foot Print Ratio have a significant difference in the mean values for both feet in both sexes. There is a low coefficient of variation. The $P$ values are also are significant. A standard FPR value was derived. Utilizing these values sex determination was done by comparing it with the each of the already calculated FPR values. The percentage accuracy of establishing sex by this method is $80 \%$ which is significant.
\end{abstract}

Key words: Foot print, foot print ratio, maximum length, maximum breadth.

\section{Introduction}

Establishing sex by the foot print study is rather a new approach in the ever expanding research subject of human identity.

Morphology of human foot is greatly influenced by combined effects of heredity and living style of man [1].They determine the size and shape of the foot prints and thereby make them unique data to establish human identity.

Pioneers in the science of foot prints, Paul Topinard [2] and Rudolf Martin [3] suggested a ratio of foot length to stature. Louise Robbins (4) reported on the possibilities of establishing the height and weight of a person from foot print. However, evidence of sexual dimorphism for the foot print in the literature being meager at present [1] makes the subject open for further research.

The Foot Print Ratio (FPR) is derived as a ratio between the two parameters of the foot prints i.e. the maximum width and maximum length, measured in millimeters \& given as follows.

Maximum width of the foot print (in mms)

Maximum length of the foot print (in mms)

The purpose of the study is to assess the reliability and applicability of assessing sex identity by deriving FPR from foot prints and thereby provide additional evidence to the foot print study in sex identity.

\section{Materials And Methods}

Four hundred dermatoglyphic foot prints of 100 males $\& 100$ females were obtained from the staff and undergraduate students of Government Medical College Aurangabad. The age group of these persons was in the range of 17 to 50 years. All the individuals were having healthy and normal feet.

Foot prints were taken using following method.

1. Before obtaining the prints, the persons were asked to wash their soles with soap and dry them for getting clear prints.

2. Plain white glossy drawing paper was used.

3. Kores duplicating ink was used.

4. For smearing the ink on the sole, special ball prepared from cotton and gauze was used.

5. White drawing paper was kept on a clean smooth and hard surface (tile) to ensure good prints. 
Before the foot was lifted off the paper, using a sharp pointed pencil tip, certain anatomical land marks of the feet were noted and marked on the paper close to foot print.

a. Mid rear heal point (Pterion)

b. Median metatarsal point

c. Lateral metatarsal point

The foot prints obtained so were then numbered and filed together noting the information about the name, age and sex.

On completion of taking the foot prints, sole of each foot was cleansed with cotton wool soaked in acetone, removing all ink stains and then advised to wash again with soap and water themselves.

For measuring the dimensions of foot prints, Robbins method was applied. Using a transparent millimeter scale, these dimensions was measured referring to the land marks on the paper earlier while taking the print as described below.

a) Maximum Length: (Fig.1) It was measured from mid-rear heal point of reference called Pterion to the point of reference at the front end of the foot print, at the anterior most point of whichever toe that was tallest.

b) Maximum Breadth: (Fig.2) It was measured across the ball portion of the foot print, from the medial metatarsal to lateral metatarsal point, land marks sites marked.

\section{Results}

The Footprints Ratio (FPR) for both left and right foot prints of each individual in the study group was calculated separately and values obtained were analyzed statistically. Summary of statistical analysis of these values was tabulated in Table 1.From Table 1; it follows that the Foot Print Ratio has a significant difference in the mean values for both the feet in both sexes. There is a low coefficient of variation. The $\mathrm{P}$ values are also significant.

Table 1: Statistical break down analysis of Foot Print Ratio of the foot prints

\begin{tabular}{|c|c|c|c|c|c|c|}
\hline \multirow[b]{2}{*}{$\begin{array}{l}\text { Foot print } \\
\text { Side }\end{array}$} & \multicolumn{3}{|c|}{ Mean value (S.D.) } & \multicolumn{2}{|c|}{ Coefficient of Variation } & \multirow[b]{2}{*}{$\begin{array}{l}T \text { test unpaired } \\
\text { and } P \text { value }\end{array}$} \\
\hline & $\begin{array}{c}\text { Male } \\
\mathrm{n}=\mathbf{1 0 0}\end{array}$ & $\begin{array}{c}\text { Female } \\
n=100\end{array}$ & $\begin{array}{c}\text { Mean } \\
\text { Difference }\end{array}$ & Male & Female & \\
\hline Right & $\begin{array}{c}0.370 \\
(+-0.0161)\end{array}$ & $\begin{array}{c}0.364 \\
(+-0.0187)\end{array}$ & 0.006 & 4.35 & 5.137 & $\begin{array}{c}2.446 \\
\mathrm{P}<0.05\end{array}$ \\
\hline Left & $\begin{array}{c}0.370 \\
(+-0.016)\end{array}$ & $\begin{array}{c}0.364 \\
(+-0.0180)\end{array}$ & 0.006 & 4.02 & 4.94 & $\begin{array}{l}2.121 \\
\mathrm{P}<0.05\end{array}$ \\
\hline
\end{tabular}

If $t$ value more than 2 then $P$ is less than 0.05 i.e. it is significant.

With these values in hand, a sex prediction scheme was worked out as mentioned below.

A standard FPR value was derived at first for each of the left and right foot print separately using the scheme.

Standard Foot Print Ratio (SFPR)

$=\frac{\text { Minimum FPR in male with SD }+ \text { Maximum FPR in female with SD }}{2}$

$=\underline{(\text { Male mean FPR-SD })+(\text { Female mean FPR }+ \text { SD })}$

Standard values thus calculated are tabulated in table 2

Table no. 2: Standard Foot Print Ratio (SFPR) values

\begin{tabular}{|c|c|}
\hline $\begin{array}{c}\text { Foot Print } \\
\text { (side) }\end{array}$ & SFPR value \\
\hline Right & 0.3683 \\
\hline Left & 0.368 \\
\hline
\end{tabular}

Utilizing these values sex determination was done by comparing it with the each of the already calculated FPR values from each participant in following order.

Every FPR value of Right and Left Foot Prints upto the limits of the SFPR values 0.3683 and 0.368 respectively (Table 2) were reported as Female sex while those values above these limits reported as male sex. Percentage accuracy of reporting of sex identity by this method is then checked in the data record sheet as the true sex of each participant is known and entered in it (Table 3). About $75 \%$ accuracy was found in this method. To be exact for Right side male $82 \%$, Right side female $79 \%$, Left side male $76 \%$ and Left side female $70 \%$ foot prints were sexed correctly. 


\begin{tabular}{|c|c|c|c|c|}
\hline Sex & Side & $\begin{array}{l}\text { No. of prints } \\
\text { studied }\end{array}$ & $\begin{array}{c}\text { No. of prints } \\
\text { sex reported } \\
\text { correctly } \\
\end{array}$ & $\begin{array}{l}\text { Percent } \\
\text { Incidence }\end{array}$ \\
\hline \multirow{2}{*}{ Male } & Right & 100 & 82 & 82 \\
\hline & Left & 100 & 76 & 76 \\
\hline \multirow{2}{*}{ Female } & Right & 100 & 79 & 79 \\
\hline & Left & 100 & 70 & 70 \\
\hline
\end{tabular}

Figure No. 1 and Figure No.2: Showing the method of measuring the maximum length and the maximum breath of the foot in the subjects.

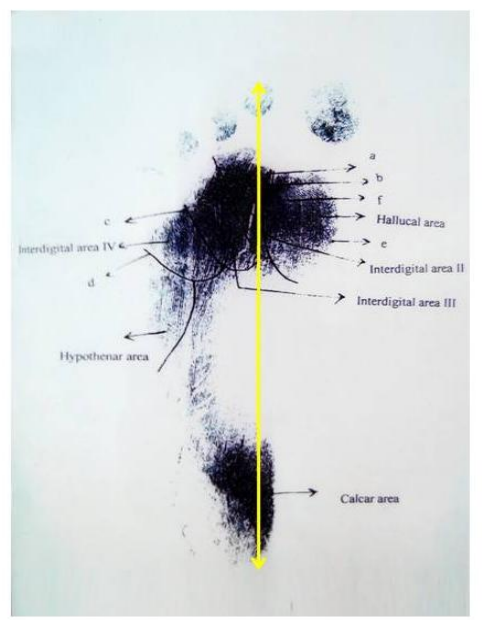

Figure No. 1

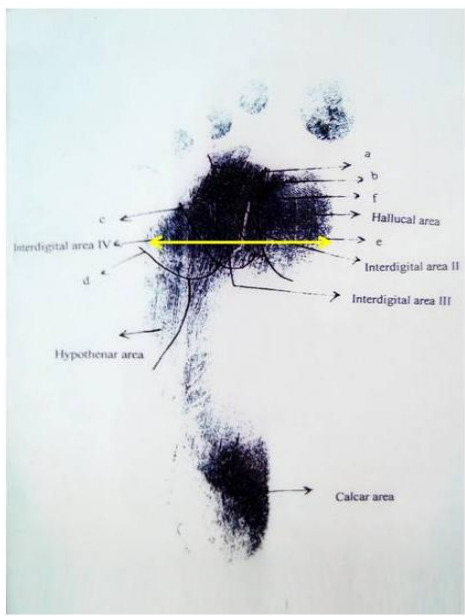

Figure No. 2

\section{Discussion}

The foot prints reflect the internal structure of the foot [6]. They can yield the information about the size and shape of bones in the feet. As the foot skeleton attains its adult proportions, a sexual differentiation also occurs in the bone structure of the feet [6]. Evans [7] from his work concluded that male bone bear stronger tensile and compression strength than the female bones. The male bones thus have robustness, brought about by the stress of the larger muscles and ligament masses. This robustness presents as an increase in the size of bones in the male [8]. The bones in the feet of the females do not show these robust traits. The size difference in these bones is thus reflected in the length and width dimensions for foot prints [6]. Thus in the present study, greater value of FPR for the foot prints of male participants compared to that of females foot prints is not a coincidence, but a fact.

The differences between the left and right foot prints in the same individual, observed in both sexes in the present study is again not a coincidence but may be explained on the basis of concept of Dominant foot [6]. Most of the individuals have a dominant foot which always supports the body to a greater extent while in standing or in walking. The shoe of this foot wears off at a faster rate than the shoe on the other side.

\section{Conclusion}

1. Sex identity by deriving the Foot Print Ratio FPR is simple, inexpensive and easy to perform, requiring no special training.

2. A Standard Foot Print Ratio (SFPR) for left and right foot prints were derived to be 0.368 and 0.3683 respectively.

3. All FPR values up to these limits predicted as female sex and those values beyond these limits predicted as male sex.

4. The percentage accuracy of establishing sex by this method is $80 \%$ which is significant. It is a reasonably reliable method of sex identification. 


\section{References}

[1] L M Robbins, The individuality of human foot prints, Journal of Forensic Sciences, 23 (N4), 1978, 778-785.

[2] P L Topinard, Anthropologie, Vol. 1,2 ${ }^{\text {nd }}$ Ed. Rainowald Ed.Paris, 1877.

[3] R Martin, Lehrbiech der Anthropologie, Gustar Fischer Jena, Vol-1(of 3), 1928.

[4] L M Robbins, Estimating height and weight from size of Foot Prints, Journal of Forensic Sciences, 31(1), 1986, 143152.

[5] M B Marie, T G Williams, A Margalet, Length of growing foot, The Journal of Bone and Joint Surgery, 38-A (5), 1956, 998-1000

[6] L M Robbins, C C Thomas, Foot Prints, Collection, Analysis and Interpretation, Springfield, 1L, 1985.

[7] F G Evans, C C Thomas, Mechanical Properties of Bones, Springfield, 1973.

[8] Singh and Singh, Identification of Sex from Tarsal Bones, Acta Anatomica, 93, 1975, 568-573.

[9] Nageshkumar G Rao, Foot Print Ratio (FPR): A Clue for Establishing Sex Identity, Journal of Indian Academy of Forensic Medicine, 12 (2), 1990. 